九州大学学術情報リポジトリ

Kyushu University Institutional Repository

\title{
Clinical study of childhood acute disseminated encephalomyelitis, multiple sclerosis, and acute transverse myelitis in Fukuoka Prefecture, Japan
}

Torisu, Hiroyuki

Department of Pediatrics, Graduate School of Medical Sciences, Kyushu University

Kira, Ryutaro

Department of Pediatrics, Graduate School of Medical Sciences, Kyushu University

Ishizaki, Yoshito

Department of Pediatric Neurology, Fukuoka Childrens Hospital Medical Center | Department of Pediatrics, Graduate School of Medical Sciences, Kyushu University

Sanefuji, Masafumi

Department of Pediatrics, Graduate School of Medical Sciences, Kyushu University

他

http://hdl. hand le. net/2324/26647

出版情報：Brain and Development. 32 (6)，pp.454-462，2010-06-01. Elsevier バージョン：

権利関係: (C) 2009 Elsevier B.V. 
Title: Clinical study of childhood acute disseminated encephalomyelitis, multiple sclerosis and acute transverse myelitis in Fukuoka Prefecture, Japan

Authors: Torisu $\mathrm{H}^{1}$, Kira $\mathrm{R}^{1}$, Ishizaki $\mathrm{Y}^{1,2}$, Sanefuji $\mathrm{M}^{1}$, Yamaguchi $\mathrm{Y}^{1}$, Yasumoto $\mathrm{S}^{3}$, Murakami $\mathrm{Y}^{4}$, Shimono $\mathrm{M}^{5}$, Nagamitsu $\mathrm{S}^{6}$, Masuzaki $\mathrm{M}^{7}$, Amamoto $\mathrm{M}^{8}$, Kondo $\mathrm{R}^{9}$, Uozumi $\mathrm{T}^{10}$, Aibe $\mathrm{M}^{11}$, Gondo $\mathrm{K}^{12}$, Hanai $\mathrm{T}^{2}$, Hirose $\mathrm{S}^{3}$, Matsuishi $\mathrm{T}^{6}$, Shirahata $\mathrm{A}^{5}$, Mitsudome $\mathrm{A}^{3}$, and Hara $\mathrm{T}^{1}$

\section{Institutional Affiliations:}

1. Department of Pediatrics, Graduate School of Medical Sciences, Kyushu University, Fukuoka, Japan

2. Department of Pediatric Neurology, Fukuoka Childrens Hospital Medical Center, Japan

3. Department of Pediatrics, School of Medicine, Fukuoka University, Fukuoka, Japan

4. Department of Pediatrics, Omuta City General Hospital, Omuta, Japan

5. Department of Pediatrics, University of Occupational and Environmental Health, Kitakyushu, Japan

6. Department of Pediatrics and Child Health, Kurume University School of Medicine, Kurume, Japan

7. Department of Pediatrics, Fukuoka University Chikushi Hospital, Fukuoka, Japan

8. Department of Pediatrics, Emergency and Critical Care Medical Center, Kitakyushu Municipal Yahata Hospital, Kitakyushu, Japan

9. Department of Pediatrics, Aso Iizuka Hospital, Iizuka, Japan

10. Department of Pediatrics, Nippon Steel Yawata Memorial Hospital, Kitakyushu, Japan

11. Department of Pediatrics, Kyushu Rosai Hospital, Kitakyushu, Japan

12. Department of Pediatrics, Kitakyushu Municipal Medical Center, Kitakyushu, Japan 
Correspondence: Hiroyuki Torisu, M.D., Ph.D.,

Department of Pediatrics, Graduate School of Medical Sciences, Kyushu University, 3-1-1 Maidashi, Higashi-ku, Fukuoka 812-8582, Japan.

Tel. + 81-92-642-5421, Fax. +81-92-642-5435,

E-mail address: htorys@pediatr.med.kyushu-u.ac.jp

Running titles: ADEM clinical study in Japan (28 characters including spaces)

Key Words: Acute disseminated encephalomyelitis, multiple sclerosis, transverse myelitis, incidence, MRI, epidemiology, incidence

Text: 24 pages. Abstract: 247 words. Figure: 2 (no color image). Tables: 3. 


\section{Abstract}

Acute disseminated encephalomyelitis (ADEM) has recently been studied in several countries owing to the development and wide spread use of imaging technology, but few epidemiological studies of childhood ADEM have been undertaken in Asian countries. To perform a comprehensive survey of ADEM and related diseases in Japanese children, we conducted a multicenter, population-based study on childhood ADEM, multiple sclerosis and acute isolated transverse myelitis in Fukuoka Prefecture, Japan. We identified 26 children with ADEM, 8 with multiple sclerosis, and 4 with acute transverse myelitis during five years between September 1998 and August 2003. The incidence of childhood ADEM under the age of 15 years was 0.64 per 100,000 person- years, mean age at onset was 5.7 years, and male-female ratio was 2.3:1. The prevalence of childhood multiple sclerosis was 1.3 per 100,000 persons. The mean age at onset of multiple sclerosis, 9.3 years, was significantly higher than that of ADEM. Nineteen (73\%) and four (15\%) patients with ADEM experienced antecedent infectious illnesses and vaccinations, respectively, within one month before the onset. Clinical and radiological findings of ADEM revealed that the frequency of seizures, mean white blood cell counts in cerebrospinal fluid, and the frequency of subcortical lesions in Fukuoka study, seemed to be higher than those in previous non-Asian studies. These findings suggest that there are ethnic or geographical differences in the incidence and clinical features of ADEM, and that there might be potent genetic or environmental risk factors for ADEM distinct from those for multiple sclerosis. 


\section{Introduction}

Acute disseminated encephalomyelitis (ADEM) is typically a monophasic acute encephalomyelitis with multiple lesions in the central nervous system (CNS). It occurs with a variety of neurological symptoms after infection or immunization, and could end with spontaneous remission [1-5]. The characteristic pathological feature is non-vasculitic inflammatory demyelination. ADEM is basically considered as secondary encephalomyelitis by autoreactive immune response based on the findings of experimental autoimmune encephalomyelitis.

Due to the difficulty in diagnosing ADEM by a constellation of histories, symptoms, signs, and laboratory findings, the clinical features were not been well investigated until brain-imaging technology had developed. The widespread use of MRI machines has facilitated the diagnosis of ADEM, and consequently several studies have been undertaken to reveal clinical and radiological features [6-20]. Population-based epidemiologic data on the incidence and clinical features of ADEM had been lacking, but two distinct studies have been recently reported [13, 16]. One was conducted in a defined, sizeable population of San Diego, California [13], and the other was a nationwide survey in Germany [16]. More studies are needed to determine whether there are geographic and ethnic variations in the incidence and clinical features of ADEM.

In the present study, to reveal epidemiologic and clinical aspects of Japanese childhood ADEM, we undertook a multicenter, population-based study in Fukuoka Prefecture in southern Japan. For comparison, we additionally assessed the epidemiology of multiple sclerosis and transverse myelitis. 


\section{Patients and Methods}

Fukuoka Prefecture is located in northern Kyushu Island, the third largest island in Japan (figure 1). It is positioned between 33 and 34 degrees North latitude, and has an area of 4,974 $\mathrm{km}^{2}$. The climate is relatively mild. The annual average temperature is 17.2 degrees Celsius and the average annual precipitation is roughly $2018 \mathrm{~mm}$, with very little snowfall. According to census figures, Fukuoka Prefecture had 4.96 million people in total and 0.73 million people was under 15 years of age on October 1, 2003. It has five major medical centers for children: Kyushu University Hospital, Fukuoka University Hospital, Kurume University Hospital, University of Occupational and Environmental Health Hospital, and Fukuoka Children's Hospital. The children with neurological problems in Fukuoka Prefecture are admitted to these medical centers and affiliated hospitals and are treated by certified pediatric neurologists.

In November 2003, we first sent all those hospitals the a questionnaire about the number of patients with ADEM, multiple sclerosis and acute isolated transverse myelitis hospitalized or consulted during the five years between September 1998 and August 2003. We received answers from all major medical centers and affiliated hospitals in Fukuoka Prefecture. Then all patients were registered in this study, and certified pediatric neurologists reviewed all medical records including age, sex, family history, previous history, signs and symptoms, laboratory findings, MR images, treatment, and short-term outcome. As for the patients with ADEM or acute isolated transverse myelitis, we performed additional research into the subsequent disease evolution in November 2008.

We made a diagnosis of ADEM according to a modified definition from the literature [7-9]: 1) acute onset of CNS symptoms, 2) MRI findings of multiple T2 prolonged lesions in the CNS white matter without old lesions, 3) no history of a previous clinical episode with features of a demyelinating event, and 4) elimination of infectious encephalitis, collagen disease, and metabolic disease. We also eliminated encephalitis with cortical lesions. The diagnosis of acute isolated transverse myelitis was based on 1) acute onset of spinal symptoms, 2) MRI findings of segmental T2 prolonged lesion in spinal 
cord, and 3) elimination of infectious encephalitis, collagen disease, and metabolic disease. Multiple sclerosis was diagnosed according to Poser's criteria [22].

Statistical analysis was performed using chi-square, Fisher's exact, and Mann-Whitney tests. A p-value $<0.05$ was considered to be statistically significant.

This research was approved by the research ethnics committee of Kyushu University. 


\section{Results}

\section{GENERAL EPIDEMIOLOGICAL FINDINGS}

Table 1 presents a summary of epidemiological data. A total of 38 patients from five major medical centers and their affiliated hospitals were registered. Twenty-six children fulfilled the diagnostic criteria for ADEM, 8 for multiple sclerosis, and 4 for acute transverse myelitis.

\section{$A D E M$}

The incidence of childhood ADEM under the age of 15 years in Fukuoka prefecture was 0.64 per 100,000 person- years. The distribution of the age at presentation had one major peak, and the mean age at onset was 5.7 years (range 11months-15years) (figure 2). The male-female ratio of 2.3:1 tended to be higher compared with that in the normal population, although it did not reach statistical significance $(\mathrm{p}=$ 0.06). There was no definite gender difference in the age at onset (male 5.9 years, female 5.2 years). Twenty-two patients (85\%) developed ADEM before 10 years of age. There was no family history of neurological disease except one patient whose mother affected hereditary neuropathy with pressure palsies [18].

No seasonal clustering of ADEM patients was noted. Within 1 month before the onset of neurological symptoms of ADEM, 19 patients (73\%) showed antecedent infectious illnesses; upper respiratory tract infections (6 patients), acute gastroenteritis (1 patient), aseptic meningitis (1 patient), influenza (1 patient), hand-foot-mouth disease ( 1 patient) and nonspecific febrile illnesses ( 9 patients). Causal organisms of the illness were identified in only 4 patients; mycoplasma (2 patients), influenza virus (1 patient), enterovirus 71(1 patient). Four patients (15\%) had vaccinations within 1 month before the onset of neurological symptoms; Japanese encephalitis virus, rubella virus, hepatitis B virus, and poliovirus vaccines. The other three patients $(12 \%)$ had neither episode of febrile illness nor any vaccination.

The mean onset ages of infection- and vaccine-associated ADEM were 6.2 and 3.2 years, respectively. The mean latency between the onset of neurological symptoms and antecedent illness or vaccination was 17.7 days (range 2-35 days). There was no definite difference in the latent periods between 
infection- and vaccine-associated ADEM (17.8 and 17.0 days, respectively).

\section{Multiple sclerosis}

The prevalence of multiple sclerosis under the age of 15 years was 1.3 per 100,000 persons in 2003 . Of 8 patients with multiple sclerosis, 5 were male and 3 female. The mean age at onset was 9.3 years (range 3-12 years), and 6 patients (75\%) presented after 10 years of age (figure 2). The age distribution of multiple sclerosis was significantly different from that of $\operatorname{ADEM}(p=0.02)$. Of 8 patients with multiple sclerosis, 4 patients showed upper respiratory tract infections or nonspecific febrile illnesses within 2 weeks before the onset of neurological symptoms. Causal organism was not identified. Mean duration between the onset and some illness was 7.5 days (range 2-14 days).

\section{Acute transverse myelitis}

The incidence of acute isolated transverse myelitis was 0.11 per 100,000 person-years. Of 4 patients with acute transverse myelitis, one was male and 3 female. The mean age at onset was 6.3 years (range 2-13 years). All four patients had acute transverse myelitis from October to December. One patient showed nonspecific febrile illnesses 5 days before the onset of spinal symptoms. No children had vaccinations within 1 month before the onset.

\section{CLINICAL FINDINGS}

Clinical features of the three diseases are summarized in Table 2.

\section{ADEM}

Systemic symptoms proceeding to neurological ones included fever in 19 ADEM patients (73\%), headache in 10 patients (38\%) and vomiting in 8 patients $(31 \%)$. The neurological symptoms included gait disturbance in 14 patients (54\%), disturbed consciousness in 13 patients (50\%), seizures in 8 patients (31\%), dysarthria in 4 patients (15\%), urinary retention in 5 patients (19\%), visual impairment in 3 patients (12\%), psychotic symptoms in 3 patients (12\%), and sensory disturbance in 2 patients (8\%). Pyramidal motor signs occurred in 16 patients (62\%). Neck stiffness was observed in 6 patients (23\%). 
Cranial nerve abnormalities including ophthalmoplegia, dysarthria and dysphagia occurred in 8 patients (31\%). Five patients (19\%) presented with cerebellar symptoms.

Twenty-two patients had EEG results. All EEGs showed increased slow waves on background activities without paroxysmal discharges. We did not identify the patients with epilepsy among ADEM patients.

\section{Multiple sclerosis}

Four patients with multiple sclerosis (50\%) had systemic symptoms preceding neurological ones; fever in 4 patients (50\%) and headache in 3 patients (38\%). The CNS symptoms in the first attack of multiple sclerosis included gait disturbance in 5 patients (63\%), visual disturbance in 5 patients (63\%), disturbed consciousness in 3 patients (38\%), urinary retention in 1 patient (13\%), sensory disturbance in 1 patient (13\%). Also, a single 12-years-old patient had a convulsion during the first attack. In the clinical course, cranial nerve abnormalities (ophthalmoplegia, dysarthria, and dysphagia) occurred in 4 patients (50\%). Five patients (63\%) presented with cerebellar symptoms. Psychotic symptoms occurred in 2 patients $(25 \%)$.

\section{Acute transverse myelitis}

Two patients with acute isolated transverse myelitis showed fever, headache and nausea as prodromal symptoms. All patients showed gait disturbance as the earliest spinal symptoms. Three patients showed urinary retention, and 2 patients presented with sensory disturbance.

\section{LABORATORY FINDINGS}

Blood and cerebrospinal fluid (CSF) examinations were undertaken in all patients.

\section{ADEM}

The first blood examination revealed leukocytosis $\left(>10,000 / \mathrm{mm}^{3}\right)$ in 16 ADEM patients $(62 \%)$ (mean 12,300/ $\mu 1$, range 3,280 - 30,500/ $\mu 1$ ) and mild or no elevation of C-reactive protein concentration $(<1.5 \mathrm{mg} / \mathrm{dl})$ of 24 patients $(92 \%)$ (mean $0.31 \mathrm{mg} / \mathrm{dl}$, range $0-14.5 \mathrm{mg} / \mathrm{dl})$. The first CSF 
examination showed pleocytosis $(>20 / \mu 1)$ in 21 patients $(81 \%)($ mean $105 / \mu 1$, range $0-608 / \mu 1)$ and protein elevation (>40mg/dl) in 9 patients (35\%) (mean $35 \mathrm{mg} / \mathrm{dl}$, range $10-73 \mathrm{mg} / \mathrm{dl})$. Oligoclonal bands in CSF were measured in 18 patients, but no patients showed the intrathecal synthesis.

\section{Multiple sclerosis}

Two patients with multiple sclerosis (25\%) showed leukocytosis on the first blood examination, and all patients showed mild or no elevation of C-reactive protein concentration (mean $0.22 \mathrm{mg} / \mathrm{dl}$, range 0-0.9 mg/dl). The first CSF examination revealed pleocytosis in three patients (38\%) (mean 22/ $\mathrm{mm}^{3}$, range $0-90 / \mathrm{mm}^{3}$ ) and protein elevation in two patients $(25 \%)$ (mean $32 \mathrm{mg} / \mathrm{dl}$, range $18-46 \mathrm{mg} / \mathrm{dl}$ ). Oligoclonal bands in CSF were measured in seven patients and 1 patient (14\%) showed a positive result.

\section{Acute transverse myelitis}

Two patients with acute transverse myelitis showed leukocytosis on the first blood examination (mean $13,400 / \mathrm{mm}^{3}$, range $6,300-24,200 / \mathrm{mm}^{3}$ ), and 3 patients showed mild or no elevation of C-reactive protein (mean $0.55 \mathrm{mg} / \mathrm{dl}$, range $0.0-1.9 \mathrm{mg} / \mathrm{dl}$ ). The first CSF examination showed pleocytosis in 2 patients (mean $73 / \mathrm{mm}^{3}$, range $2-154 / \mathrm{mm}^{3}$ ) and protein elevation in 2 patients (mean $47 \mathrm{mg} / \mathrm{dl}$, range 16 - $66 \mathrm{mg} / \mathrm{d}$ ). Oligoclonal band in CSF was examined in 1 patient, and was detected.

\section{MRI FINDINGS}

MR brain scans were performed in all children. The results are summarized in Table 2.

\section{ADEM}

More than three lesions were found in 24 ADEM patients (92\%). All patients had cerebral lesion, and 10 patients (38\%) had cerebral lesions alone. Eight patients (31\%) had lesions in cerebellum, 6 patients (23\%) in brainstem, 6 patients (23\%) in spinal cord, and 2 patients (8\%) in optic nerves. In cerebrum, periventricular lesions were found in 12 patients (46\%), subcortical lesions were found in 24 patients (92\%), basal ganglia lesions in 8 patients (31\%), thalamus lesions in 6 patients (23\%), internal capsule 
lesions in 6 patients (23\%), and corpus callosum lesions in 3 patients (12\%). Twenty-one patients had gadolinium-enhanced MRI study, and 7 patients demonstrated contarast-enhancement.

\section{Multiple sclerosis}

MRI demonstrated more than 3 lesions in 5 patients with multiple sclerosis (63\%). Lesions affecting periventricular white matter were found in 5 patients (63\%), subcortical white matter in 5 patients (63\%), basal ganglia in 3 patients (38\%), and thalamus in 2 patients (25\%). One patient had cerebral lesions alone. Seven patients $(88 \%)$ had lesions in brainstem, 7 patients $(88 \%)$ in cerebellum, and 1 patient in optic nerves. No patients showed any spinal lesions. The lesions had gadolinium enhancement in 6 patients $(75 \%)$,

\section{Acute transverse myelitis}

All patients with acute transverse myelitis had spinal lesions and no lesions in other parts of CNS.

\section{TREATMENT AND OUTCOME}

All patients with ADEM, multiple sclerosis, and acute transverse myelitis had adequate treatments and recovered without significant sequelae during the study period. Table 2 summarizes the results. In Japan we do not have standardized treatment-guidelines for ADEM, so this study could not demonstrate a treatment-prognosis relationship.

\section{ADEM}

High-dose methyl-prednisolone ( 20 - $30 \mathrm{mg} / \mathrm{kg} / \mathrm{day}$ ) for 3days was given to 22 patients with ADEM (85\%), and oral steroid alone to 2 patients. One patient had intravenous immunoglobulin therapy. These therapies were all effective and no patient died. Nineteen patients (73\%) completely recovered, and 7 patients (27\%) had neurological sequelae involving mild motor disturbance (2 patients), visual impairment (2 patients), cerebellar ataxia (1 patient), bladder dysfunction (1 patient), cognitive impairment (1 patient), and epilepsy (1 patient). All patients with vaccine-associated and idiopathic 
ADEM had complete recovery. Additional investigation in 2008 revealed that the ADEM patients had no subsequent demyelinating events, during the observation period of 6.6 years on average.

\section{Multiple sclerosis}

During the 5-year study period, high-dose methyl-prednisolone was given to 7 patients with multiple sclerosis and oral steroid alone to 1 patient. And these therapies were all effective. Three patients completely recovered. Five patients had neurological sequelae involving mild motor disturbance (2 patients), cerebellar ataxia (3 patients), visual impairment (1 patient), dysphagia (1 patient), and psychotic problem (1 patient).

\section{Acute transverse myelitis}

High-dose methyl-prednisolone was given to 3 patients with acute transverse myelitis, and oral steroid alone to 1 patient. One patient had intravenous immunoglobulin therapy. These steroid therapies were all effective. The effectiveness of intravenous immunoglobulin therapy was obscure. All patients completely recovered, and developed no recurrence of a demyelinating event. 


\section{Discussion}

In the present study, we performed a multicenter, population-based study of childhood ADEM and related diseases in Fukuoka Prefecture in southern Japan. The data revealed an incidence and clinical and MRI features of ADEM in Japanese children. Furthermore, the results showed that the incidence of childhood ADEM was higher than that of childhood multiple sclerosis, and that the age of onset was younger in ADEM compared with that in multiple sclerosis.

There remains a controversy over diagnostic criteria for ADEM. In this study, we emphasized 1) acute onset, 2) showing signs and symptoms of CNS, 3) multiple lesions on white matter, 4) exclusion of collagen diseases or metabolic diseases. In addition, we investigated past histories and laboratory findings including viral studies, and exclude encephalitis with cortical lesions. To increase diagnostic accuracy, we confirmed the diagnosis in 2003 and 2008.

In 2007, new diagnostic criteria for ADEM were proposed by International Pediatric MS Study Group [21]. However there was no critical difference between these criteria and ours, although we will use these new criteria for subsequent research with $\mathrm{ADEM}$ in our patients.

\section{General epidemiological aspect of ADEM and related diseases}

Few systematic studies of ADEM in populations have been undertaken. A study conducted in San Diego country first reported epidemiologic and clinical features of ADEM in a defined, sizeable population [13]. As shown in Table 3, the incidence of childhood ADEM in Fukuoka, 0.64 per 100,000 person-years, is almost the same as that in San Diego, 0.4 per 100,000 person-years under 20 years of age, with a peak incidence of 0.8 per 100,000 for age strata between 5 and 9 years of age. Contrary to the Fukuoka and San Diego studies, a recent nationwide survey on pediatric ADEM and multiple sclerosis in Germany reported that the incidence of ADEM, 0.07 per 100,000 person-years under 16 years of age, was very low, while the incidence of pediatric multiple sclerosis, 0.3 per 100,000 person-years, was unexpectedly high [16]. Multiple sclerosis on the initial episode may be indistinguishable from ADEM, but the majority of ADEM patients would not be subsequently affected 
with multiple sclerosis because of the risk of 0 - 28\% [1]. Therefore, these conflicting data may not be attributed to diagnostic issues, but imply that there are ethnic or geographical differences in the incidence of ADEM. It is an intriguing question whether the prevalence of ADEM is higher in the northern countries, as is the case for multiple sclerosis; more epidemiological studies are needed. In the prevaccine era, encephalomyelitis complicating measles, rubella, or varicella was relatively common, and could be explained through immune-mediated mechanism in the pathogenesis of perivenular demyelination [24]. Epidemiologic research in the 1960s-70s revealed the incidences of measles, rubella, and varicella encephalitis were about 1 per 1,000, 1-2 per 10,000, and 3 per 10,000 infected persons, respectively [25-27]. On the other hand, the incidence of vaccination-associated encephalomyelitis was much lower (e.g. 0.1-0.2 per 100,000 in measles-vaccinated persons), after vaccination forms with high rates of complications were no longer in use [28]. In recent epidemiologic studies $[13,16]$ as well as the present study, no patients with measles-, rubella-, and varicella-related ADEM were reported. Thus, it is possible that endemic infectious agents markedly influence the incidence of childhood ADEM. The prevention of the major infectious agents associated with ADEM could lead to a reduction of its occurrence.

The mean age at presentation of ADEM was 5.7 years in our study. The age distribution of ADEM exhibited a striking concordance between other epidemiologic studies, and appeared to be markedly different from that of MS with the majority of patients over 10 years of age [29]. The male-female ratio of 2.3:1 in the present study tended to be higher, although it did not reach statistical significance. A previous pediatric cohort revealed a significant male dominance in ADEM [9], and most other studies including the San Diego and Germany surveys also showed a tendency for male dominance [6,7,8-16], as opposed to a female preponderance for multiple sclerosis. These findings suggest that there might be potent genetic or environmental risk factors for ADEM distinct from those for multiple sclerosis.

\section{Clinical features of ADEM}

The clinical features of childhood ADEM in the Fukuoka and San Diego studies were similar, but the 
frequency of seizures, mean white blood cell counts in CSF, and the frequency of subcortical lesions in Fukuoka study appeared to be higher than those in the San Diego study [13] . On the other hand, the frequency of vomiting, altered mental status, and lesions in basal ganglia/thalamus and brainstem in Fukuoka study seemed to be lower. Japanese ADEM patients might have a tendency to have subcortical lesions, and thus the frequency of seizure and CSF pleocytosis were highly seen. There might be distinctive clinical features of ADEM in Asia, which are expected to associate with location of lesions. In this study, none of the ADEM patients was observed to develop multiple sclerosis in the subsequent 6.6 years of follow-up. A recent ADEM cohort study revealed that 24 (18\%) ofl32 patients had second attack within average follow-up period of five years, but that 15 of 24 patients had second attack within 6 months [30]. Even a few years of follow-up could elevate the diagnostic accuracy of ADEM. Retrospective study of several years could show a low ratio of multiple sclerosis development.

\section{The difference between ADEM subtypes}

The incidence of the infection-associated type was five times higher than that of vaccine-associated type. Consistent with recent studies, infection-associated ADEM was the major type in the present study. The distributions of age at onset were different between infection- and vaccine-associated ADEM, since Japanese children have vaccination mainly in early childhood. However, the latency between the onset of neurological symptoms and antecedent infection or vaccination and the laboratory data were not different between both subtypes of ADEM. These results suggest that subtypes of ADEM share a similar pathophysiological mechanism.

\section{The difference of ADEM, multiple sclerosis and transverse myelitis}

The number of patients with multiple sclerosis or acute transverse myelitis in this present study was insufficient to delineate the epidemiologic and clinical features. However, the results revealed that the age of onset was younger in ADEM than that in multiple sclerosis, and that the leukocytosis and pleocytosis were present in most ADEM patients while usually it was not found in multiple sclerosis.

This study showed a low positive rate of oligoclonal bands in children with multiple sclerosis. 
Recent studies revealed that oligoclonal bands develop over the course of the disease [29]. Our results might be affected by timing of the examination.In Japan the positive rate of CSF oligoclonal bands in multiple sclerosis patients, especially opticospinal multiple sclerosis, is known to be lower than that in western countries.

These findings support the empirical findings about the difference between ADEM and multiple sclerosis.

\section{Conclusions}

In conclusion, our multicenter, population-based study demonstrated that the incidence of childhood ADEM was estimated at 0.64 per 100,000 person-years and was much higher than that of childhood multiple sclerosis in Fukuoka Prefecture, Japan. A nationwide survey with larger sample sizes is necessary to obtain further epidemiologic evidence for the development of ADEM as well as its related disease. 


\section{Acknowledgements}

This work was supported in part by the Health and Labour Sciences Research Grant on Intractable Diseases (Neuroimmunological Diseases) from the Ministry of Health, Labour and Welfare of Japan and the Grant-in-Aid for Scientific Research (17591095, 20591225) from and the Ministry of Education, Culture, Sports, Science and Technology of Japan.

There is no conflict of interest in the work reported in the present manuscript. 


\section{References}

1. Tenembaum S, Chitnis T, Ness J, Hahn JS, for the International Pediatric MS Study Group. Acute disseminated encephalomyelitis. Neurology 2007;68(Suppl 2):S23-36.

2. Rust RS. Multiple sclerosis, acute disseminated encephalomyelitis, and related conditions. Semin Pediatr Neurol 7: 66-90, 2000.

3. Garg RK. Acute disseminated encephalomyelitis. Postgrad Med J 2003;79:11-7.

4. Menge T, Hemmer B, Nessler S, Wiendl, H. Neuhaus O, Hartung HP, et al. Acute disseminated encephalomyelitis. An update. Arch Neurol 2005;62: 1673-80.

5.Kimura S, Nezu A, Ohtsuki N, Kobayashi T, Osaka H, Umehara S. Serial magnetic resonance imaging in children with postinfectious encephalitis. Brain Dev 1996;18; 461-5.

6. Dale RC, de Sousa C, Chong WK, Cox TC, Harding B, Neville BG Acute disseminated encephalomyelitis, multiphasic disseminated encephalomyelitis and multiple sclerosis in children. Brain 2000;123:2407-22.

7. Hynson JL, Kornberg AJ, Coleman LT, Shield L, Harvey AS, Kean MJ. Clinical and neuroradiologic features of acute disseminated encephalomyelitis in children. Neurology 2001;56:1308-12.

8. Murthy KSN, Faden HS, Cohen ME, Bakshi R. Acute disseminated encephalomyelitis in children. Pediatrics 2002;110: 21-8.

9. Tenembaum S, Chamoles N, Fejerman N. Acute disseminated encephalomyelitis: a long-term follow-up study of 84 pediatric patients. Neurology 2002;59:1224-31.

10. Anlar B, Basaran C, Kose G, Guven, A, Haspolat S, Yakut A. et al. Acute disseminated encephalomyelitis in children: outcome and prognosis. Neuropediatrics 2003;34:194-9.

11. Gupte G, Stonehouse M, Wassmer E, Coad NA, Whitehouse WP. Acute disseminated encephalomyelitis: a review of 18 cases in childhood. J Paediatr Child Health 2003;39:336-42.

12. Mikaeloff Y, Suissa S, Vallee L, Lubetzki C, Ponsot G, Confavreux C, et al. First episode of acute CNS inflammatory demyelination in childhood: prognostic factors for multiple sclerosis and 
disability. J Pediatr 2004;144:246-52.

13. Leake JA, Albani S, Kao AS, Senac MO, Billman GF, Nespeca MP, et al. Acute disseminated encephalomyelitis in childhood: epidemiologic, clinical and laboratory features. Pediatr Infect Dis J $2004 ; 23: 756-64$.

14. Idrissova ZhR, Boldyreva MN, Dekonenko EP, Malishev NA, Leontyeva IY, Martinenko IN, et al. Acute disseminated encephalomyelitis in children: clinical features and HLA-DR linkage. Eur J Neurol 2003;10:537-46.

15. Schwarz S, Mohr A, Knauth M, Wildemann B, Storch-Hagenlocher B. Acute disseminated encephalomyelitis: a follow-up study of 40 adult patients. Neulorogy 2001;56:1313-8.

16. Pohl D, Hennemuth I, von Kries R, Hanefeld F. Paediatric multiple sclerosis and acute disseminated encephalomyelitis in Germany: results of a nationwide survey. Eur J Pediatr 2007;166:405-12.

17. Weng WC, Peng SS, Lee WT, Fan PC, Chien YH, Du JC, Shen YZ. Acute disseminated encephalomyelitis in children: one medical center experience. Acta Pediatr Taiwan 47: 67-71, 2006

18. Lin CH, Jeng JS, Hsieh ST, Yip PK, Wu RM. Acute disseminated encephalomyelitis: a follow-up study in Taiwan. J Neurol Neurosurg Psychiatry 78: 162-7, 2007

19. Hung KL, Liao HT, Tsai ML. The spectrum of postinfectious encephalomyelitis. Brain Dev 23: $42-5,2001$

20. Khong PL, Ho HK, Cheng PW, Wong VC, Goh W, Chan FL. Childhood acute disseminated encephalomyelitis: the role of brain and spinal cord MRI. Pediatr Radiol 32:59-62, 2002.

21. Krupp LB, Banwell B, Tenembaum S, for the International Pediatric MS Study Group. Consensus definitions proposed for pediatric multiple sclerosis and related childhood disorders. Neurology 68(supple 2):S7-S12, 2007

22. Poser CM, Paty DW, Scheinberg L, McDonald WI, Davis FA, Ebers GC, et al. New diagnostic criteria for multiple sclerosis: guidelines for research protocols. Ann Neurol 1983;13:227-31.

23. Muneuchi J, Tokunaga Y, Kira R, Gondo K, Hara T. Acute disseminated encephalomyelitis in a 
female with hereditary neuropathy with susceptibility to pressure palsy. Pediatr Neurol $2000 ; 22: 302-4$

24. Johnson RT, Griffin DE, Hirsch RL, Wolinsky JS, Roedenbeck S, Lindo de Soriano I, et al. Measles encephalomyelitis--clinical and immunologic studies. NEngl J Med 1984;310:137-41.

25. Miller DL. Frequency of Complications of Measles, 1963. Report on a National Inquiry by the Public Health Laboratory Service in Collaboration with the Society of Medical Officers of Health. Br Med J 1964;2:75-8.

26. Centers for Disease Control: Encephalitis surveillance: Annual summary 1978. Issued May 1981.

27. Centers for Disease Control: Encephalitis surveillance: Annual summary 1977. Issued May 1979.

28. Fenichel GM. Neurological complications of immunization. Ann Neurol 1982;12: 119-28.

29. Banwell B, Krupp L, Kennedy J, Tellier R, Tenembaum S, Ness J, et al. Clinical features and viral serologies in children with multiple sclerosis: a multinational observational study. Lancet Neurol 2007;6:773-81.

30.Mikaeloff Y, Caridade G, Husson B, Suissa S, Tardieu M; Neuropediatric KIDSEP Study Group of the French Neuropediatric Society. Acute disseminated encephalomyelitis cohort study: prognostic factors for relapse. Eur J Paediatr Neurol 2007:90-5. 


\section{Figure Legends}

Figure 1. Geographic location of Fukuoka Prefecture, Japan

Figure 2. Age and gender distribution of patients with ADEM (A) and multiple sclerosis (B). 
Table 1 Epidemiologic features of patients with ADEM , multiple sclerosis, and acute transverse myelitis

\begin{tabular}{|c|c|c|c|c|c|c|}
\hline & ADEM & & & & MS & ATM \\
\hline & $\begin{array}{l}\text { Total } \\
\mathrm{N}=26\end{array}$ & $\begin{array}{l}\text { Infection- } \\
\text { associated } \\
\mathrm{N}=19\end{array}$ & $\begin{array}{l}\text { Vaccine- } \\
\text { associated } \\
\quad \mathrm{N}=4\end{array}$ & $\begin{array}{l}\text { Idiopathic } \\
\qquad N=3\end{array}$ & $\mathrm{~N}=8$ & $\mathrm{~N}=4$ \\
\hline $\begin{array}{l}\text { Incidence rate, } \\
/ 100,000 \text { person/year }\end{array}$ & 0.64 & 0.47 & 0.10 & 0.07 & - & 0.11 \\
\hline Prevalence, $/ 100,000$ person & - & - & - & - & 1.3 & - \\
\hline Mean age at onset, y (range) & $5.7(0-15)$ & $6.2(1-15)$ & $3.2(0-5)$ & $6.3(4-9)$ & $9.3(3-12)$ & $6.3(2-13)$ \\
\hline Male/Female & $18 / 8$ & $14 / 5$ & $3 / 1$ & $1 / 2$ & $6 / 3$ & $1 / 3$ \\
\hline $\begin{array}{l}\text { Family history of demyelinating } \\
\text { diseases, } n\end{array}$ & 0 & 0 & 0 & 0 & 0 & 0 \\
\hline Specific previous history, $\mathrm{n}$ & 2 & $2^{a}$ & 0 & 0 & 0 & 0 \\
\hline Preexisiting disease, $n$ & 4 & $3^{\#}$ & $1^{\# \#}$ & 0 & 0 & 0 \\
\hline Antecedent event, $\mathrm{n}$ & 23 & $19^{*}$ & $4^{* *}$ & 0 & $4^{\star \star \star}$ & $1^{* \star \star *}$ \\
\hline $\begin{array}{l}\text { Duration between antecedent event } \\
\text { and the onset, day (range) }\end{array}$ & $17.7(2-35)$ & $17.8(2-35)$ & $17.0(9-30)$ & - & $7.5(2-14)$ & 5 \\
\hline Season at onset & No clustering & No clustering & No clustering & No clustering & No clustering & $\begin{array}{l}\text { October to } \\
\text { Deccember }\end{array}$ \\
\hline
\end{tabular}

ADEM: Acute disseminated encephalomyelitis MS: Mutiple sclerosis ATM: Acute transverse myelitis

$\S$ Acute cerebellar ataxia and Kawasaki disease

\# Nonspecific developmental delay, phenylketourea, and heredetary neuropathy with pressure palsies \#\# Incontinentia pigmenti

* Upper respiratory tract infection, gastroenteritis, aseptic meningitis, and hand-foot-mouth disease

**Vaccination against Japanese encephalitis virus, rubella virus, polio virus, and hapatitis $B$ virus

*** Upper respiratory tract infection and nonspecific febrile illness $* * * *$ nonspecific febrile illness 
Table 2 Clinical presentation of patients with ADEM, multiple sclerosis, and acute transverse myelitis

\begin{tabular}{|c|c|c|c|c|c|c|}
\hline & \multicolumn{4}{|l|}{ ADEM } & \multirow[t]{2}{*}{ MS } & \multirow[t]{2}{*}{ ATM } \\
\hline & Total & $\begin{array}{l}\text { Infection- } \\
\text { associated }\end{array}$ & $\begin{array}{l}\text { Vaccine- } \\
\text { associated }\end{array}$ & Idiopathic & & \\
\hline & $\mathrm{N}=26$ & $\mathrm{~N}=19$ & $\mathrm{~N}=4$ & $\mathrm{~N}=3$ & $\mathrm{~N}=8$ & $\mathrm{~N}=4$ \\
\hline & $\mathrm{n}(\%)$ & $\mathrm{n}(\%)$ & $\mathrm{n}(\%)$ & $n(\%)$ & $\mathrm{n}(\%)$ & $\mathrm{n}(\%)$ \\
\hline \multicolumn{7}{|l|}{ Clinical features } \\
\hline \multicolumn{7}{|l|}{ Systemic symptoms } \\
\hline Fever & $19(73)$ & $13(68)$ & $4(100)$ & 2(67) & $4(50)$ & $2(50)$ \\
\hline Headache & $10(38)$ & $6(32)$ & $1(25)$ & $3(100)$ & $3(38)$ & $2(50)$ \\
\hline Vomiting & $8(31)$ & $4(21)$ & $3(75)$ & $1(33)$ & $0(0)$ & $2(50)$ \\
\hline \multicolumn{7}{|l|}{ Neurological symptoms } \\
\hline Gait disturbance & $14(54)$ & $12(63)$ & $1(25)$ & $1(33)$ & $5(63)$ & $4(100)$ \\
\hline Disturbed consciouness & $13(50)$ & 10(53) & $3(75)$ & $0(0)$ & $3(38)$ & $0(0)$ \\
\hline Seizures & $8(31)$ & $4(21)$ & $3(75)$ & $1(33)$ & $1(13)$ & $0(0)$ \\
\hline Visual impairment & $3(12)$ & $3(16)$ & $0(0)$ & $0(0)$ & $4(50)$ & $0(0)$ \\
\hline Urinary retention & $5(19)$ & $5(26)$ & $0(0)$ & $0(0)$ & $1(13)$ & $3(75)$ \\
\hline Cranial nerve abnormalities & $8(31)$ & $5(26)$ & $3(75)$ & $0(0)$ & $4(50)$ & $0(0)$ \\
\hline Cerebellar symptom & $5(19)$ & $5(26)$ & $0(0)$ & $0(0)$ & $5(63)$ & $0(0)$ \\
\hline \multicolumn{7}{|l|}{ Treatment } \\
\hline High dose mPSL & $22(85)$ & $17(89)$ & $3(75)$ & $2(67)$ & $7(88)$ & $3(75)$ \\
\hline Oral PSL alone & 2(8) & $1(5)$ & $0(0)$ & $1(33)$ & $1(13)$ & $0(0)$ \\
\hline IVIg & $1(4)$ & $1(5)$ & $1(25)$ & $0(0)$ & $5(63)$ & $1(25)$ \\
\hline \multicolumn{7}{|l|}{ Shor-term prognosis } \\
\hline Complete recovery & $19(73)$ & $12(63)$ & $4(100)$ & $3(100)$ & $3(38)$ & $4(100)$ \\
\hline \multicolumn{7}{|l|}{ MRI findings } \\
\hline More than 3 lesions & 24(92) & 18(95) & $4(100)$ & $2(67)$ & $5(63)$ & $0(0)$ \\
\hline Cerebral lesion & $26(100)$ & $19(100)$ & $4(100)$ & $3(100)$ & $7(88)$ & $0(0)$ \\
\hline Cerebral alone & $10(38)$ & $5(26)$ & $3(100)$ & 2(67) & $1(13)$ & $0(0)$ \\
\hline Periventricular WM & $12(46)$ & $8(42)$ & $3(75)$ & 1(33) & $5(63)$ & $0(0)$ \\
\hline Subcortical WM & $24(92)$ & $17(89)$ & $4(100)$ & $3(100)$ & $5(63)$ & $0(0)$ \\
\hline Basal ganglia & $8(31)$ & 7(37) & $1(25)$ & $0(0)$ & $3(38)$ & $0(0)$ \\
\hline Thalamus & $6(23)$ & $5(26)$ & $1(25)$ & $0(0)$ & $2(25)$ & $0(0)$ \\
\hline Brainstem lesion & $6(23)$ & $5(26)$ & $1(25)$ & $0(0)$ & $7(88)$ & $0(0)$ \\
\hline Cerebellum lesion & $8(31)$ & $7(37)$ & $0(0)$ & $1(33)$ & $7(88)$ & $0(0)$ \\
\hline Spinal cord lesion & $6(23)$ & $6(32)$ & $0(0)$ & $0(0)$ & $0(0)$ & $4(100)$ \\
\hline Optic nerve lesion & $2(8)$ & 2(11) & $0(0)$ & $0(0)$ & $1(13)$ & $0(0)$ \\
\hline \multicolumn{7}{|c|}{ ADEM:Acute disseminated encephalomyelitis MS:Mutiple sclerosis ATM:Acute transverse myelitis } \\
\hline \multicolumn{7}{|c|}{ mPSL:methyl-predonisolone IVIg:intravenous immunoglobulin WBC:white blood cells CRP:C-reactive protein } \\
\hline $\begin{array}{l}\text { CSF: cerebrospinal fluid WM: white } \\
\text { Effectiveness of IVlg for ATM was }\end{array}$ & 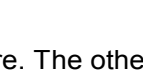 & tho to & offoctive & & & \\
\hline
\end{tabular}


Table 3 Difference in the epidemiologic features of Childhood ADEM among Fukuoka, San Diego (13), and German (16) studies

\begin{tabular}{lccc}
\hline Epidemiological data & Fukuoka & San Diego & Germany \\
\hline & & & \\
Study type & Retrospective & Retro- and prospective & Retrospective \\
Location, latitude & $33-34$ degrees north & $32-33$ degrees north & $48-54$ degrees north \\
Population & $732,942<15 y$ & $855,633<20 y$ & $13,883,539<16 y$ \\
Study duration & $1997-2003(5$ years $)$ & $1991-2000$ & $1997-1999$ \\
No. of patients & 26 & 42 & 28 \\
Mean age at onset, y (range) & $5.7(0.9-15)$ & $6.5(0.8-18)$ & $6.6(1-14)$ \\
No. of patients whose age & $20(77)$ & $27(64)$ & $23(82)$ \\
at onset is 2-10y, $\mathrm{n}(\%)$ & $2.3(18: 8)^{\mathrm{a}}$ & $1.6(26: 16)$ & $1.3(16: 12)$ \\
Sex (M:F) & 0.64 & 0.40 & 0.07 \\
Incidence, & No clustering & Winter/spring & - \\
/100,000 person /year & $23(88)$ & $39(93)$ & - \\
Seasonal clustering & 4 & $2 *$ & - \\
Antecedent event, $\mathrm{n}(\%)$ & & & \\
Immunization, $\mathrm{n}$ & & & \\
& & &
\end{tabular}

"The male-female ratio in the ADEM patients tended to be increased compared with that in the normal population $(p=0.06)$.

* Varicella and MMR, pneumococcal conjugate vaccine 
Figure 1

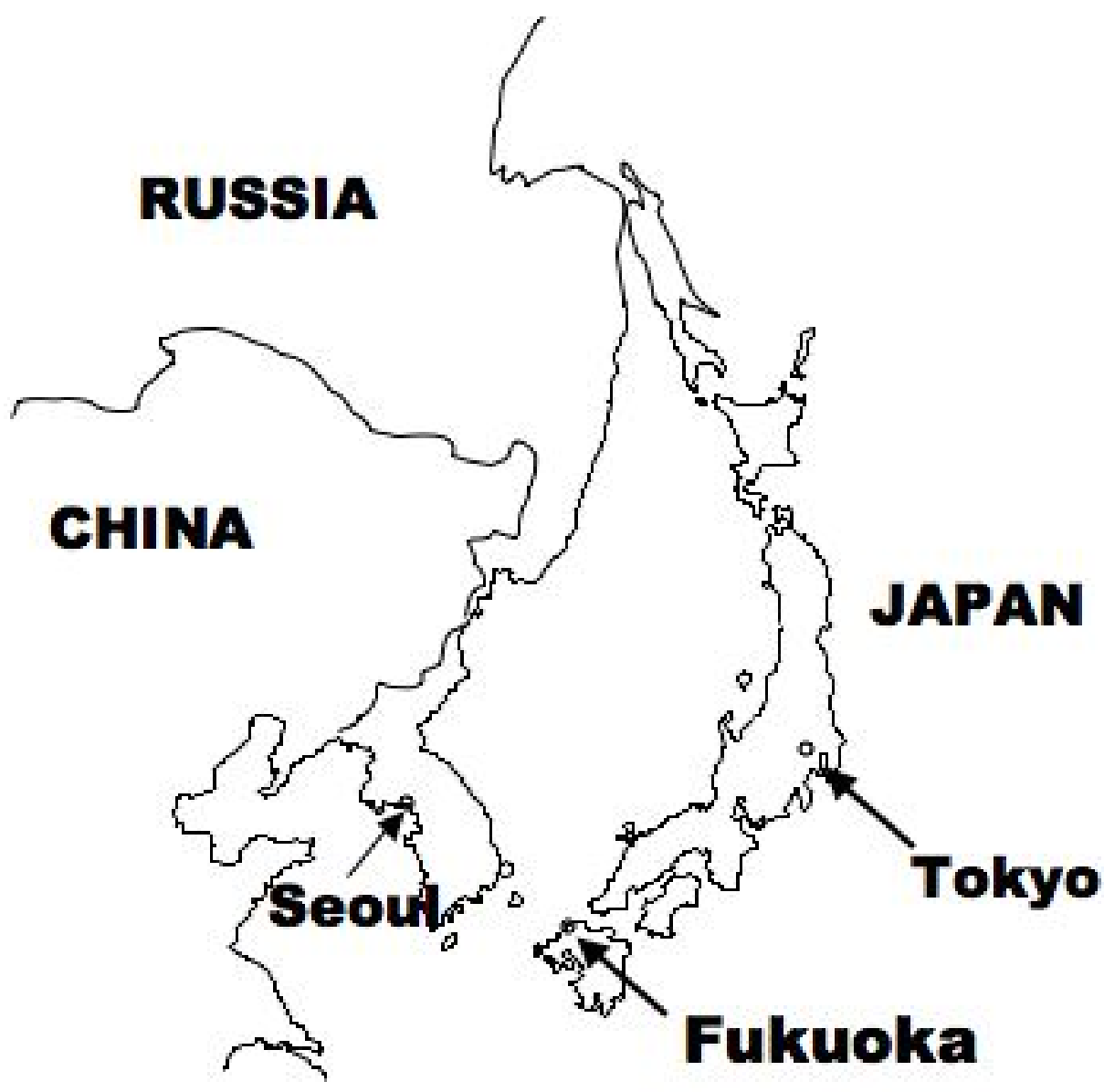

\section{Fukuoka Pref.}

N34

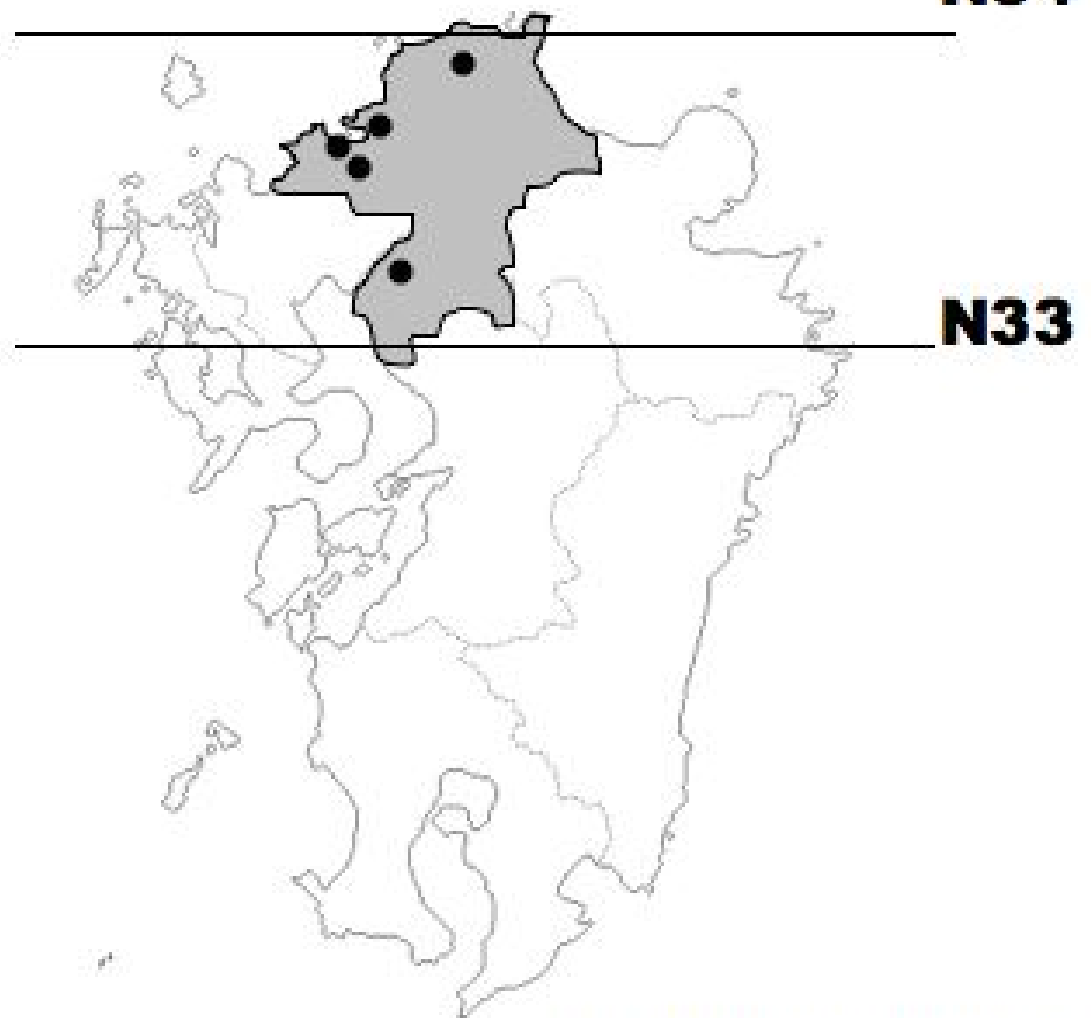

- Main Medical Center 
Figure 2
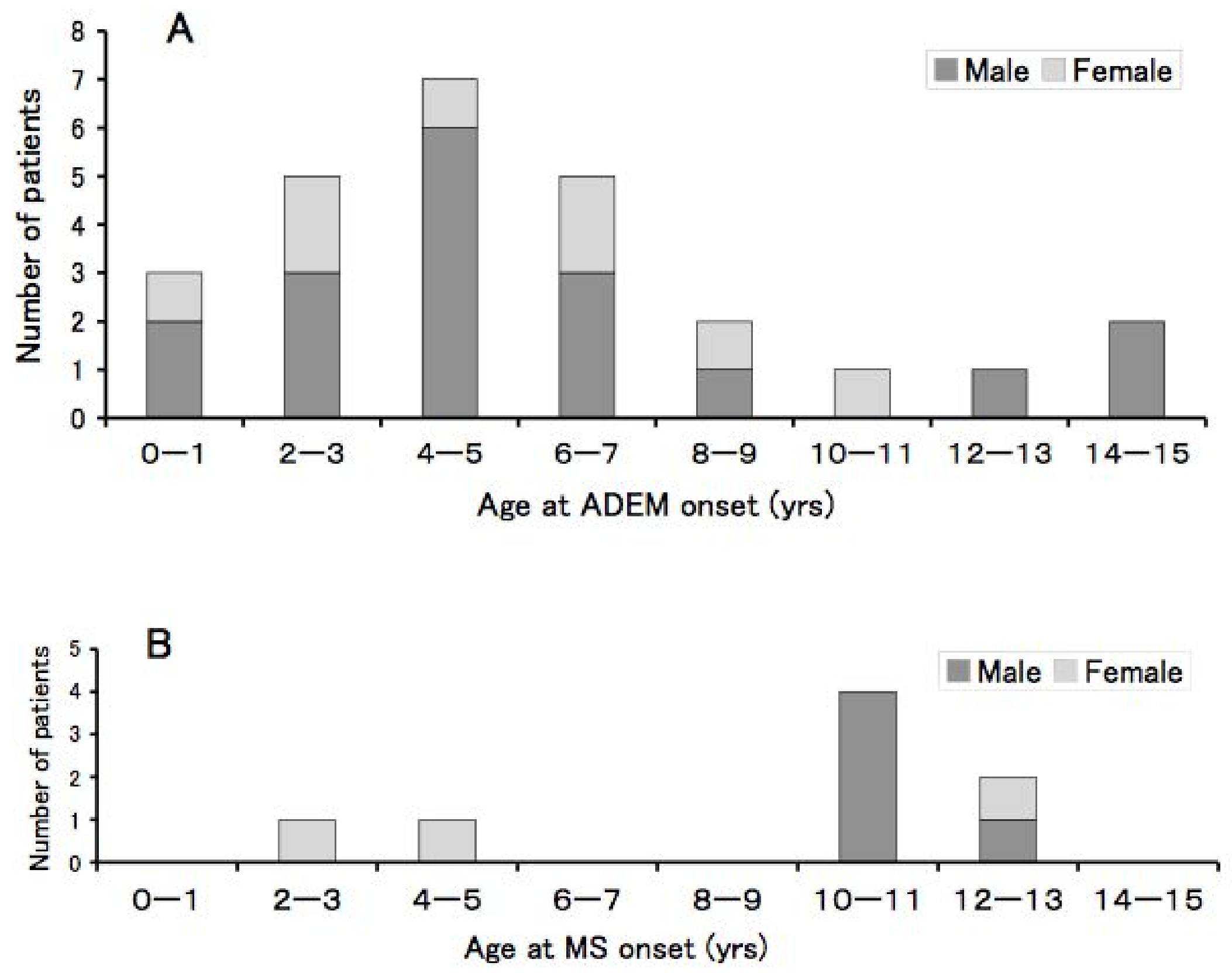